\title{
LATERAL VELOCITY VARIATIONS IN SOUTHERN CALIFORNIA. II. RESULTS FOR THE LOWER CRUST FROM Pn WAVES
}

\author{
By Thomas M. Hearn* and Robert W. Clayton
}

\begin{abstract}
A tomographic inversion of the Pn arrivals in Southern California yields new information about wave velocities and topography on the Moho discontinuity. We produce maps of $P n$ velocity and $P n$ station delays. The $P n$ velocities do not show the dramatic correlation with surface faults that is found for the shallower $\mathbf{P g}$ arrivals (Hearn and Clayton, 1986). This implies that the lower crust and mantle are largely decoupled from the upper crust. Undoubtedly, this is due to the different responses of the brittle upper crust and the ductile lower crust to tectonic and isostatic stresses. Detachment faults must play an important role in separating the crust.

In general, velocities on the American plate are higher than on the Pacific plate, but no distinct transition is observed. The Colorado River region has extremely thin crust due to basin-and-range type extension. The Transverse Ranges have a small root as seen in the station delays and which also results in slightly lower Pn velocities there. The Peninsula Ranges also have slow Pn velocities, but they do not have late station delays. Any root to the Peninsula Ranges must be very narrow. Isostatic balance must be maintained primarily through lateral density contrasts.
\end{abstract}

\section{INTRODUCTION}

Travel times from the Southern California array are used here to investigate the velocity structure of the Moho discontinuity in Southern California. Dramatic differences in velocities along the surface of the mantle as well as depth to the Moho discontinuity are shown. This work is an extension of two other papers: Hearn (1984b) which discusses Moho depths in Southern California and a companion paper, Hearn and Clayton (1986), hereafter referred to as $\mathrm{HC1}$, which develops the tomographic method used here.

The primary purpose of this paper is to investigate more thoroughly lateral variations in $P n$ velocity. The Moho in Southern California is quite variable. Moho depth varies by $10 \mathrm{~km}$ and considerable anisotropy exists (Lamanuzzi, 1981; Vetter and Minster, 1981; Hearn, 1984). Other parts of the crust and mantle also show large variations. In $\mathrm{HC1}$, the upper crust is shown to have wave velocities which directly reflect the surface tectonics by clearly defining the fault zones. Upper mantle studies find a high-velocity ridge directly beneath the Transverse Ranges and low velocities underneath the Salton trough (Raikes and Hadley, 1979; Walck and Minster, 1982; Humphreys et al., 1984). A detailed study of Moho velocities can give more insight into the tectonics of Southern California and allow one to tie upper mantle structure to upper crustal structure more closely.

\section{METHOD}

The same tomographic backprojection used for $P g$ travel times described in HC1 is used. This iterative method simulataneously finds station and event delays as

\footnotetext{
* Present address: Institute for the Study of the Continents, Cornell University, Ithaca, New York 14853.
} 
well as the lateral variations in $P n$ velocity. It is based upon a linearized version of the travel-time equation for refracted arrivals (Hearn, 1984b).

$$
t_{i j}=a_{i}\left(s_{0}\right)+b_{j}\left(s_{0}\right)+\sum_{k=0}^{n} \Delta_{i j k} s_{k}-2 F s_{0}
$$

This equation decomposes the travel time, $t_{i j}$, between station $i$ and event $j$ into three variable terms and a constant. The parameters $a_{i}$ and $b_{j}$ are the delays for station $i$ and event $j$. They can be expressed as

$$
\begin{aligned}
a_{i} & =\sqrt{s_{c}^{2}-s_{0}^{2}}\left(h-z_{e}\right) \\
b_{j} & =\sqrt{s_{c}^{2}-s_{0}^{2}} h
\end{aligned}
$$

where $h$ is the refractor depth, $z_{e}$ is the event depth, and $s_{c}$ and $s_{0}$ are the crustal slowness and mean refractor slownesses, respectively. The Southern California region is divided into a grid and the slownesses, $s_{k}$, of each element are found. The term $\Delta_{i j k}$ is the distance the ray travels between station $i$ and event $j$ on the refractor face in cell $k$. The $F$ is the horizontal distance the ray travels between the refractor and the surface. Since this equation is applied to zero mean residuals, the term with $s_{0}$ in equation (1) is assumed to be zero.

In tracing the ray across the grid, the ray is traced along only that portion of the refractor on which the ray actually travels. In doing this, as opposed to tracing it from event to station, the delays are automatically corrected so that they all refer to the same refractor slowness, $s_{0}$ (Hearn, 1984b). This way, the delays can be correctly compared to each other. Note that the delays can only be determined within a constant factor so that only the relative magnitudes of the delays matter. The station delays are directly interpretable in terms of velocity and structure.

The backprojection scheme is quite straightforward. The $P n$ travel-time branch is visually windowed from the rest of the data (Figure 1). A line is then fit to the data and all residuals computed. Station and event delays are estimated by computing the average residual at each station and event. The slowness in each cell is estimated by computing the average apparent slowness for all rays passing through each cell weighted by the distance squared. The slowness image and the two sets of delays are then scaled to minimize the weighted $\mathrm{rms}$ residual. The iterative process converges quickly.

One of the artifacts of backprojection algorithms is azimuthal bias. When ray paths are predominantly from one azimuth, the slowness anomalies are blurred preferentially along that azimuth. This is compensated for by using azimuthaveraged slowness estimates in a manner similar to Humphreys et al. (1984). Each slowness estimate is the unweighted average of the mean slownesses found for each of four nonredundant azimuth sectors of ray path approach. At the end of each iteration, the station delays, event delays, and slowness image are all three scaled by multiplicative constants determined from a three-parameter regression.

This processing is basically the same as in $\mathrm{HC1}$, used for the shallower $\mathrm{Pg}$ arrivals with only a few modifications. Since there are fewer arrivals for $P n$, azimuth bias is a more severe problem; hence, azimuth weighting is used for Pn. Also, cell sizes are larger here $(10 \mathrm{~km} \times 10 \mathrm{~km})$ because there are fewer data, and it is necessary to have a statistically adequate number of rays per cell. Cells with ten or more hits 
and stations and events with five or more arrivals are used. Even so, some cells seem to collect noise, and so large damping factors are used. The station delays are corrected for $P n$ velocity variations by only tracing the ray path along the refractor for the actual path covered; for $P g$, the rays were actually traced from station to event and corrected for refractor velocity afterwards. Since $P n$ ray paths are clearly defined and the path lengths are appreciably longer than the offset distance, a refracted ray path is a more accurate representation of the true ray path here than it is for the $\mathrm{Pg}$ arrivals of $\mathrm{HC} 1$.

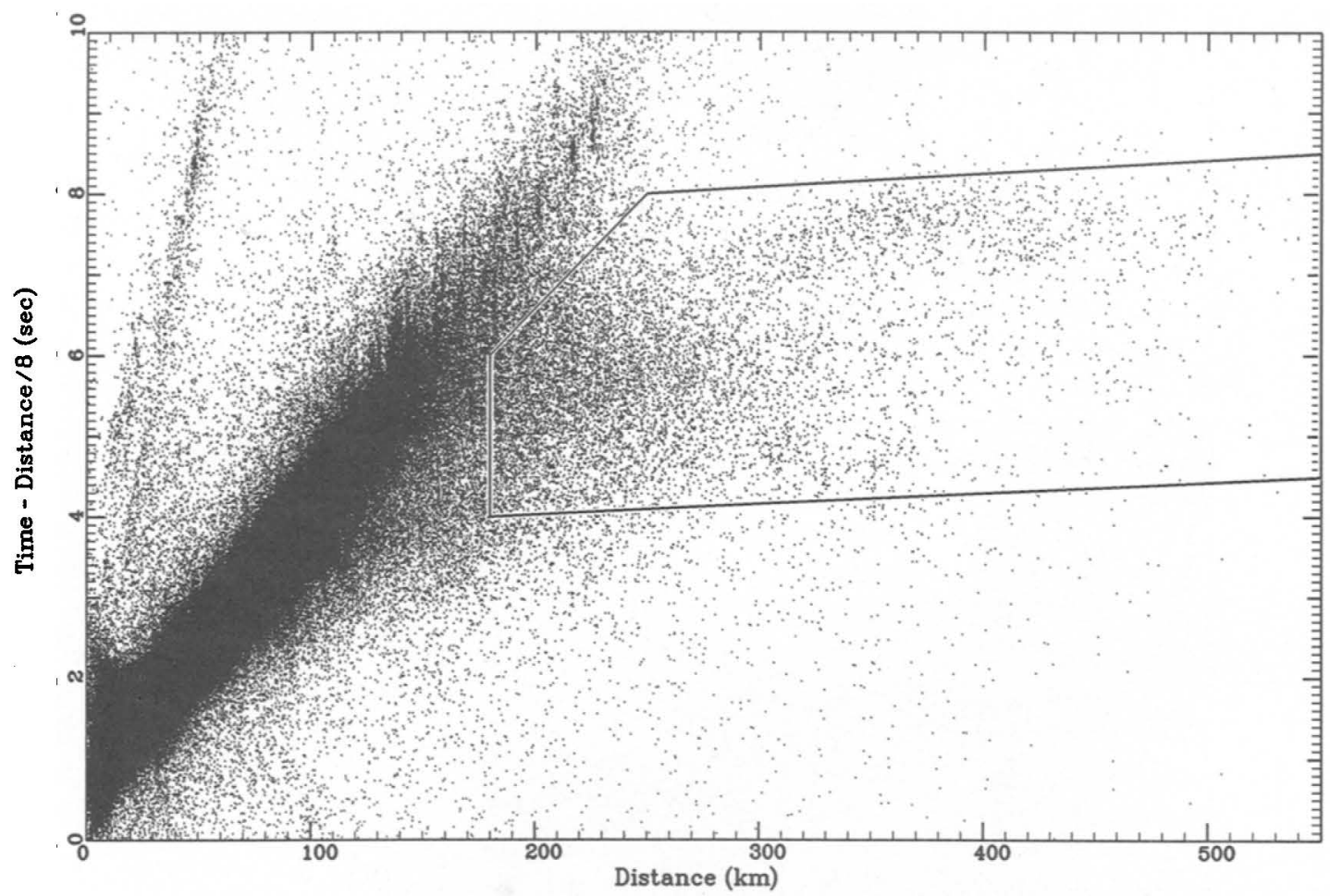

FIG. 1. Pn Data. The $P$-wave travel-time picks for $6 \mathrm{yr}$ of array data are shown as a function of source to receiver distance. The picks within the superimposed window are considered to be $P n$ arrivals. In all, over $6000 \mathrm{Pn}$ picks are displayed.

\section{The Data}

Pn data collected on the Southern California array between 1978 and 1983 were used. This travel-time branch was visually windowed from the rest of the data using a reduced travel-time plot (Figure 1). The data were weighted as the inverse variances of $400,100,25$, and 4 for quality $0,1,2$, and 3 arrivals. Quality 4 arrivals were not used. A total of 6031 arrival times from 398 events were used. This data set is of poorer quality than used in Hearn (1984) but has twice as many arrivals.

\section{VARIANCE AND RESOlUtion OF THE SOLUTION}

The $P n$ apparent velocity anomalies in Southern California are pictured at the top of Figure 2; the associated station delays are pictured at the bottom of Figure 

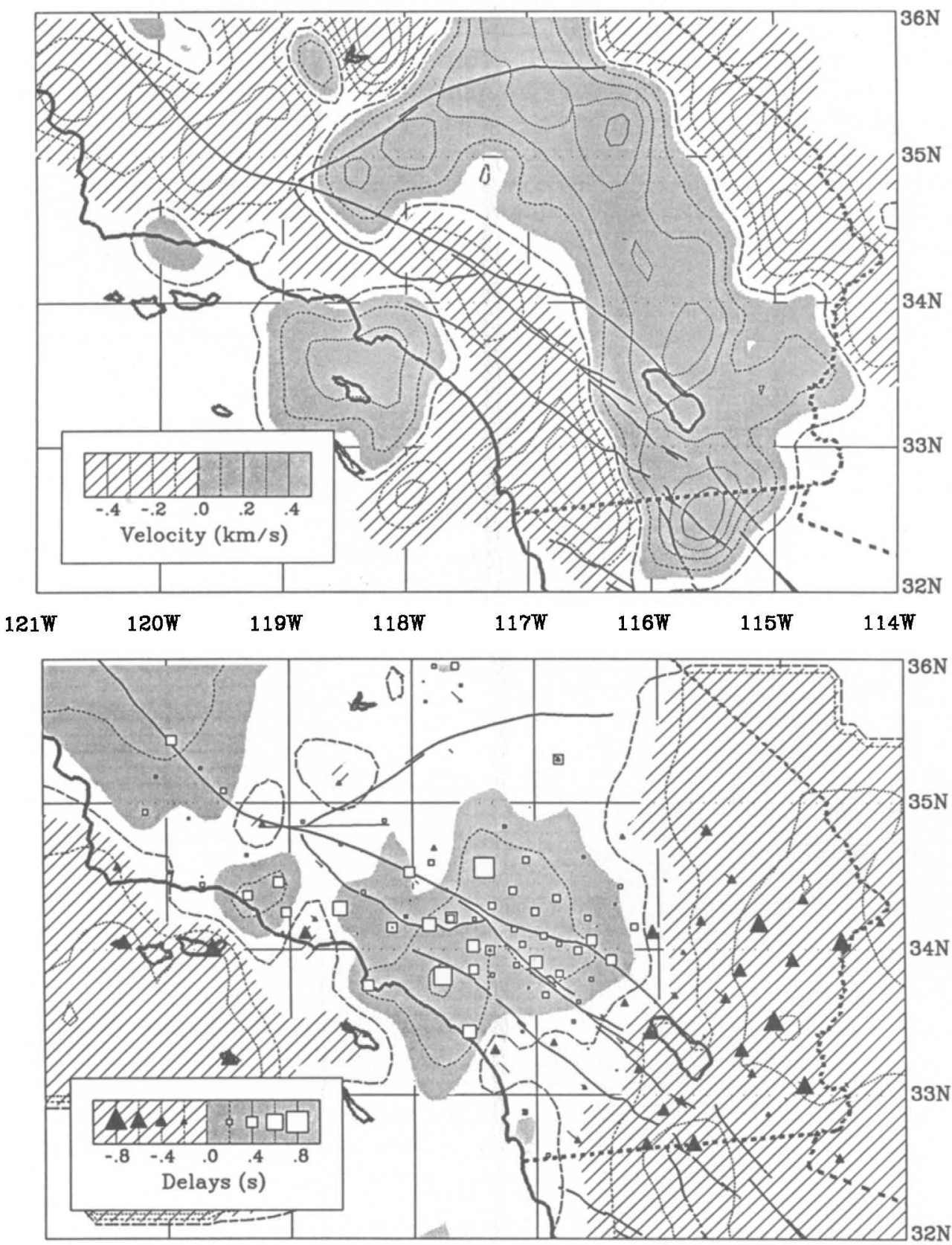

Fig. 2. Pn Results. The upper panel is a contour plot of lateral variations in Pn slowness. The hatched region indicates relatively low velocities while the shaded regions are relatively fast. In general, velocities on the American plate are higher than those on the Pacific plate. The lower panel is a contour plot showing the station delays. The hatched areas indicate regions of negative delays or early arrivals. The largest delays are associated with sedimentary basins or alluvial fans, and the smallest delays are associated with thin crust.

2. Some quite large velocity anomalies of over $1.0 \mathrm{~km} / \mathrm{sec}$ are imposed on the mean velocity of $7.8 \mathrm{~km} / \mathrm{sec}$. The Moho is at a mean depth of $30 \mathrm{~km}$, assuming a $6.2 \mathrm{~km} /$ sec crustal velocity, and a $5 \mathrm{~km}$ mean event depth. The average velocity perturbation is $0.37 \mathrm{~km} / \mathrm{sec}$. Station delays range over 2 sec. 
Both station delays and slowness distribution are quite similar to those computed earlier by Hearn (1984b). The major differences between the two sets of delays occur primarily in the Los Angeles and the Ventura basins. Differences of up to 0.4 sec exist. As tests of the tomographic method on the same data of Hearn (1984b) yielded these same results, this difference is due to the different data set and not the tomographic method. The different arrivals in this data set could be due to errors, either event location or timing, or due to undermodeling. As this data set was bulk processed, error control was not complete but hopefully the quantity of data has canceled this to some degree. Anisotropic parameters that are significant for $P n$ ray paths have been ignored (Vetter and Minister, 1981; Hearn, 1984b). If rays to these stations came predominantly from a slow direction, this could result in late static delays. Another important assumption implicitly made is that the static delays are azimuth independent. Many areas, particularly near the large basins, almost certainly have different crustal structures on opposite sides of them. This and other problems associated with not knowing the true ray path strongly affect the solution. Differences in solutions found with different ray sets demonstrate our lack of knowledge in properly modeling the ray paths.

Variance and resolution are demonstrated for the $P n$ results by using synthetic models as was done for $\mathrm{HC1}$. Travel times are found for each model using the actual ray path set. The synthetic data are then inverted in the same manner as the data. Variance is determined by using a model consisting of Gaussian noise. For a large amount of noise, $0.05 \mathrm{sec}$ standard deviation for the highest quality arrivals, the amplitudes are below that of the $P n$ anomalies. These noise results are shown in Figure 3 (top and bottom). Delay noise has a maximum value of $0.23 \mathrm{sec}$ and a slowness noise maximum of $0.24 \mathrm{~km} / \mathrm{sec}$. The absolute slowness deviation is 0.06 $\mathrm{km} / \mathrm{sec}$. Other synthetic data results show that cell responses blur $50 \mathrm{~km}$ depending on the location (Hearn, 1984a). Ray streaking due to azimuth bias is quite apparent in more poorly sampled regions.

The next synthetic is designed to investigate the slowness-delay tradeoff. The original model has horizontal stripes in the slowness image of $0.3 \mathrm{~km} / \mathrm{sec}$ and vertical stripes in the delay image of $0.15 \mathrm{sec}$. These variations are far more extreme than found in our results. Comparison of Figure 4 (top and bottom) shows the tradeoff between the crossing stripes. We see from these figures as well as from the previous results that some areas are not as well reconstructed as others. The slowness amplitude is too high by a factor of 4 , and errors in delays can be as high as $0.4 \mathrm{sec}$. The mean absolute velocity deviation is $0.46 \mathrm{~km} / \mathrm{sec}$. The northeast section of the slowness image is heavily biased by streaking along a northwest azimuth. The actual results also show signs of this effect in the region. There are a large number of events at the Coso area, at the northernmost part of the array, which contribute to streaking in the northwest azimuth. To some extent, these high velocities, and the associated sharp southwest boundary, also arise from blurring the early delays in the easternmost part of the array to the northwest. Reconstruction is most accurate in the center of the plot.

\section{Results}

In the eastern Mojave, a large amount of fast material exists. These higher velocities extend down into the Salton trough and into the Gulf of California. This is especially surprising since the Salton trough is a spreading center where hotter, lower velocity, material is expected. Indeed, Humphreys et al. (1984) find slow velocities in and under the Salton trough from teleseismic arrivals. In fact, his 

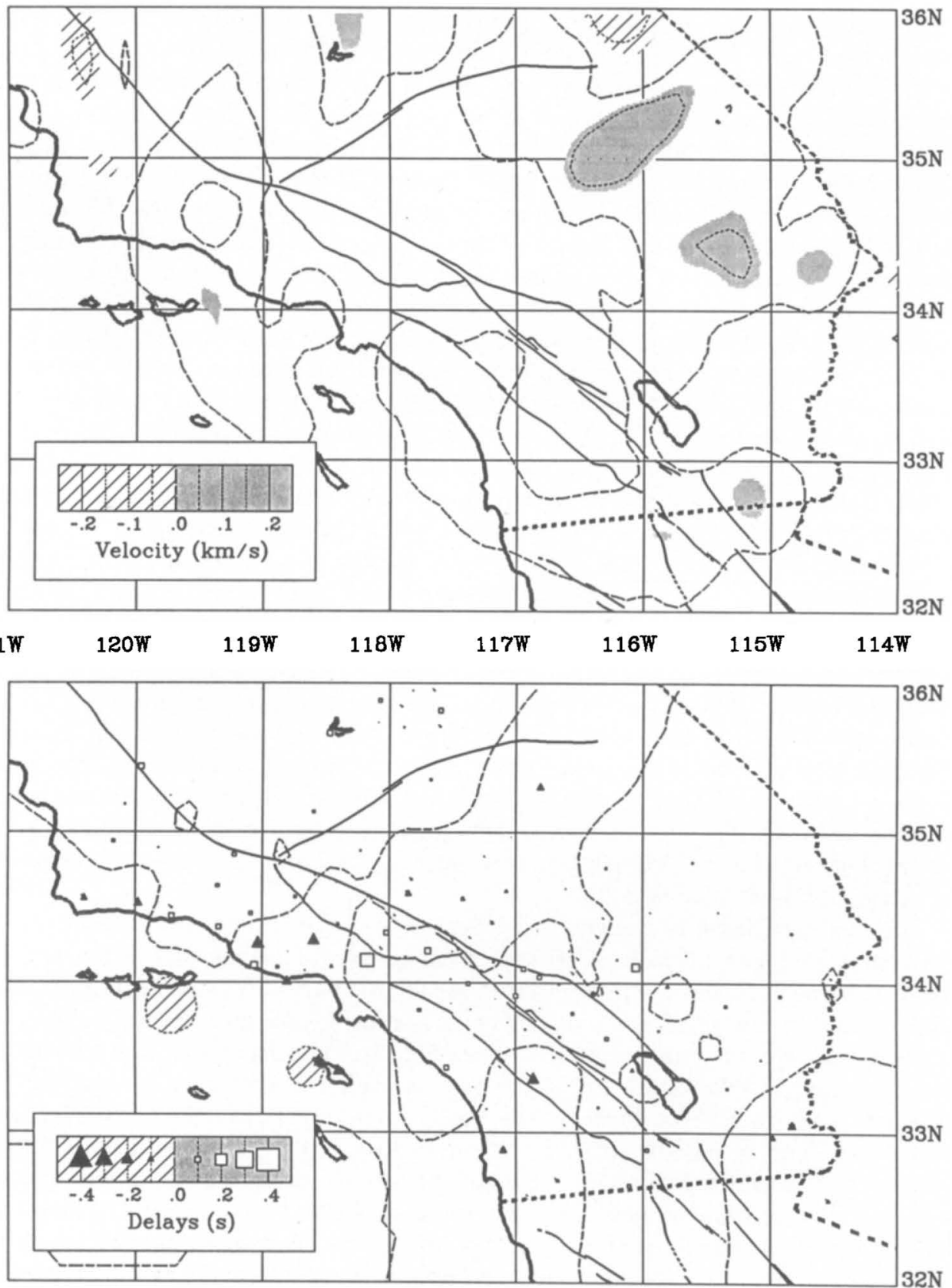

Fig. 3. Noise Test. The results of inverting random noise data with a variance similar to the actual data is shown. The upper panel gives the slowness results, while the delays are shown in the lower panel. The maximum values found are $0.24 \mathrm{~km} / \mathrm{sec}$ and $0.23 \mathrm{sec}$. These occur at poorly sampled cells and stations. The ray paths from the real $P n$ data set are used in the inversion.

cross-section has low velocities extending into the crust where high-velocity mafic material is known to exist (Fuis et al., 1982). Most likely, the actual zone of rifting in the trough is simply too narrow to resolve. The narrow dimension of the rifted zone is near $20 \mathrm{~km}$, and the resolution is not quite that good. Alternatively, the ray paths may be refracting through higher velocity material which has underplated the rift zone. 

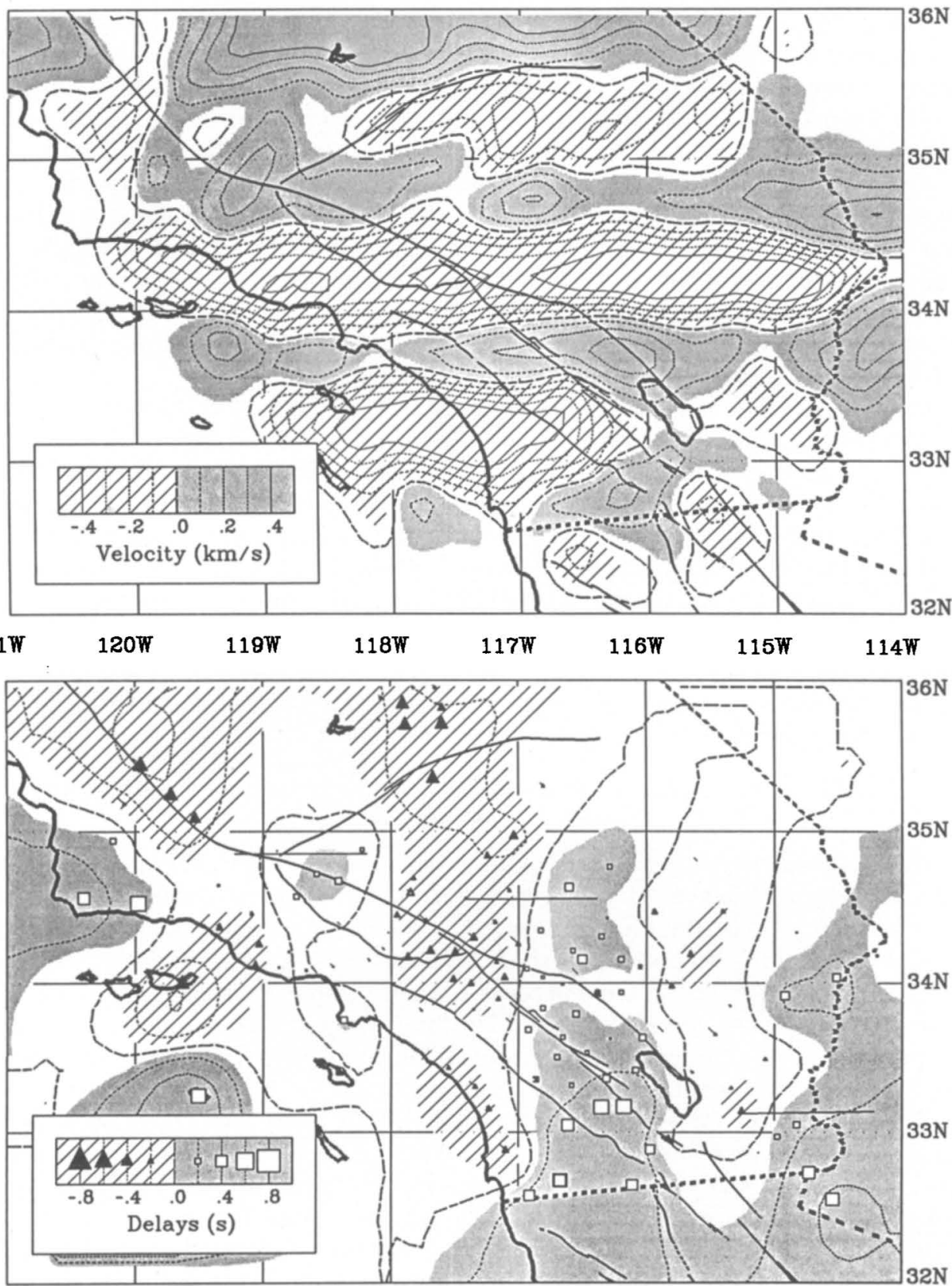

Fig. 4. Test Pattern. The results of inverting the striped model synthetic are shown. The model consists of alternating horizontal stripes of slowness variations, combined with alternating vertical stripes of delays. The synthetic is designed to show the coupling between the slowness and delay part of the solution. The input amplitudes were $\pm 0.3 \mathrm{~km} / \mathrm{sec}$ and $\pm 0.15 \mathrm{sec}$. The upper panel gives the slowness results, while the delays are shown in the lower panel. The ray paths of the real Pg data set are used in the inversion.

Slower apparent $P n$ velocities seem to underlie the Transverse Ranges and part of the Peninsular Ranges. The Transverse Ranges do show a small root in the station delays, and this is what is most likely delaying ray paths crossing this region. Similarly, the southern Sierra Nevada around Lake Isabella shows slow Pn veloci- 
ties, also due to a mountain root. A deep root is not necessarily required to cause an appreciable delay. The Peninsular Ranges show no evidence for a root in the delays, so we conclude that truly low $P n$ velocities do exist here. The slow $P n$ region in the Peninsular Ranges coincides with an area of an anomalously high isostatic gravity anomaly (Oliver, 1982) but a connection between the two is not clear.

The Mojave Desert along the Colorado River shows the early delays that have been discused in more detail in Hearn (1984b). These arrivals result from a thin 22 $\mathrm{km}$ crust that centers along the Colorado River. This region also has higher $P n$ velocities (about $8.2 \mathrm{~km} / \mathrm{sec}$ ). Structurally, $P n$ velocities in the area probably represent conditions when this portion of North America was formed while the shallow depths of the Moho represent more recent extensional tectonics associated with early basin-range extension (Zoback et al., 1981).

$P n$ velocities do not show the dramatic contrast along fault zones that was found for $P g$ rays in $\mathrm{HC1}$. Unfortunately, we do not have the resolution here that was obtained there. Velocities on the North American plate are distinctly higher than those on the Pacific plate, and the mean delays are less on the North American plate. The transition occurs over no more than $100 \mathrm{~km}$. Although the plate boundary certainly extends to Moho depth, the boundary may be a broad zone of deformation there. The results indicate that the apparent $P n$ velocities along the San Andreas have been decreased due to the root of the Transverse Ranges. These effects make defining the width of the plate boundary difficult. Furthermore, the shear stress along the plate may have reoriented the anisotropy (Vetter and Minster, 1981), thus hiding the contact.

\section{Discussion: Crustal Structure and Tectonics in Southern CALIFORNIA}

Our results show a dramatic difference in the upper crustal $P g$ velocity distribution (HC1) and the Moho velocity distribution. In the upper crust the velocity distribution clearly outlines the San Andreas, San Jacinto and other major faults in the region while on the Moho none of the boundaries exist. This separation of the crust from the mantle is undoubtedly because of their different rheological regimes. The upper crust is brittle and seismic while the lower crust is ductile and aseismic. Their responses to tectonic forces are quite different, and this has led to the separate velocity patterns for the $P g$ and the $P n$ arrivals.

One mechanism for separating the upper brittle crust from the lower, ductile crust is detachment faulting. These nearly flat faults occur at mid-crustal depths and move aseismically. Older detachments in Southern California that have been exposed at the surface include the Rand Thrust, the Pelona Thrust, and the Whipple Mountains Thrust. Recently, Crouch et al. (1984) presented reflection data which show the coastal Hosgri fault zone turning into a nearly flat fault in the mid-crust. He infers that much of the California Coast Ranges are underlain by such detachments, and their topography is largely caused by movement on these surfaces. Recent COCORP profiles in the Mojave (Cheadle et al., 1986) show many possible detachments. In $\mathrm{HC} 1$, we discuss possible detachments under the San Bernardino and San Jacinto Mountains at shallow depths. Detachment faulting is an important component in Southern California tectonics.

If these detachments occur within the upper half of the crust and continue to occur in the lower half, it is not surprising that the Moho velocity pattern is different from the upper crust. Detachment faulting effectively separates the brittle interactions on the surface from the ductile interactions at depth, thus enabling the upper 
and lower crusts to act independently. At Moho depths, the crust is responding more to the forces of tensional stretching, isostatic compensation, and convection than it is to the shear force across the plate boundary.

The thin crust of the Colorado River region may be the result of the tensional stretching that dominates the Basin and Range region. Thin crust exists in the Nevada portion (Priestly, 1982) of the Basin and Range region. In the Colorado River region, we associate the thin crust with the metamorphic core complex that exists there. Large detachment surfaces are also exposed in the region. Crustal thinning seems to have occurred by stretching of the lower crust and fracturing on normal faults in the upper crust. The detachment provides a surface separating the two regions. Zoback et al. (1981) have reviewed evidence that suggests two phases of extension in the Basin and Range region. They associate crustal thinning with the first phase of extension that occurred prior to the Miocene.

Some evidence exists for anomalously thin crust in the Salton trough (Hadley, 1978) but we associate this with the thin American plate. The American plate adjacent to the trough is thin $(22 \mathrm{~km})$ compared to the adjacent Pacific plate $(25$ $\mathrm{km}$ ). The spreading of the crust in the Salton trough occurs by the plates passively pulling apart and not by intrusions actively pushing them apart. As the plates pull apart, one might expect the thickness of newly formed crust to be near the thickness of normal ocean crust plus the sediment thickness. If such a region exists, it is too narrow to be seen without a more detailed experiment.

Isostatic balance in Southern California is a confusing issue. The eastern Transverse Ranges have a small root (Lamanuzzi, 1981). This can be seen in both the $P n$ static delays and by the slow patch in apparent $P n$ velocities. The western Transverse Ranges do not seem to have a local root but a broad root, which also balances the topographically high Antelope Valley region, that may be present. Low-gravity values (Oliver, 1982) reflect such a crustal root under the western Transverse Ranges. The isostatic balance of the Transverse Range province is complicated by the upper mantle high-velocity anomaly that underlies them (Raikes and Hadley, 1979; Walck and Minster, 1982; Humphreys et al., 1984). Statically, this anomaly should result in a broad high gravity anomaly superimposed on the crustal gravity anomalies. Dynamically, however, the high-velocity mantle anomaly should be sinking, thus pulling the crust downward to cause low-gravity values.

In contrast to the Transverse Ranges, there is little evidence for a root in the Peninsular Ranges. Although the Bouguer gravity anomaly for these ranges does show a narrow trend of low gravity following the range crest, no appreciable $P n$ delays exist. Calculation of isostatic gravity anomalies (Oliver, 1982), assuming a constant density crust, shows that a major isostatic balance problem exists in the western Peninsular Ranges. A large platform of relatively high Bouguer gravity anomaly extends from the San Diego coast inward to the Elsinore fault (Oliver, 1982). The high gravity does correspond to a patch of anomalously low $P n$ velocity but no obvious connection exists. Teleseismic results show no anomalous mantle there (Humphreys et al., 1984). If the Peninsular Ranges are in isostatic balance, it is not accomplished with a constant density crust. Their high upper crustal $\mathrm{Pg}$ velocities correspond to the high-density mafic batholith comprising the mountains. Rock densities decrease from west to east within the Peninsular Ranges (L. T. Silver, personal communication), and the $P g$ delays increase. If this trend extends sufficiently deep into the crust, then the local isostatic balance and topography can be maintained without a root.

Even if the Peninsular Ranges are isostatically balanced internally within the 
province, there still remains a problem in balancing them relative to the rest of Southern California. Despite the heavy batholiths, the observed $27 \mathrm{~km}$ average depth in the region is still less than the average California crustal thickness. The regional compensation of the Peninsular Ranges must be accomplished by a lowdensity lower crust or upper mantle or by dynamic forces produced by the plate motions. The simplest solution is to have the batholith extend only to the midcrust and overlie a low-density lower crust. Regional value could then be maintained and the local isostacy can be accomplished by lateral density gradients and by topography on the base of the Peninsular Range Batholiths.

\section{ACKNOWLEDGMENTS}

This study was supported by a research contract with the U.S. Geological Survey (14-08-001-21210) and a grant from the Sun Oil Company. Part of the graphics and computing facilities used in this study were provided by the W. M. Keck Foundation. We thank Eugene Humphreys, Leon Silver, and Hiroo Kanamori for their suggestions and reviews.

\section{REFERENCES}

Cheadle, M. J., B. L. Czuchra, T. Bryne, C. J. Ando, J. E. Oliver, L. D. Brown, S. Kaufman, P. E. Malin, and R. A. Phinney (1986). The deep crustal structure of the Mojave Desert, California, from COCORP reflection data, Tectonics (in press).

Crouch, J. K., S. B. Bachman, and J. T. Shay (1984). Post-Miocene compressional tectonics along the central California margin, in Tectonics and Sedimentation Along the California Margin, Vol. 38, Pacific Section SEPM, 35-54.

Fuis, G. S., W. D. Mooney, J. H. Healy, G. A. Mechan, and W. J. Lutter (1982). Crustal structure of the Imperial Valley Region, in The October 15, 1979 Imperial Valley Earthquake, U.S. Geol. Surv. Profess. Paper 1254, 25-50.

Hadley, D. (1978). Geophysical investigations of the structure and tectonics of Southern California, Ph.D. Thesis, California Institute of Technology, Pasadena, California.

Hearn, T. M. (1984a). Crustal structure in Southern California from array data, Ph.D. Thesis, California Institute of Technology, Pasadena, California.

Hearn, T. M. (1984b). Pn travel times in Southern California, J. Geophy. Res. 89, 1843-1855.

Hearn, T. M. and R. W. Clayton (1985). Lateral velocity variations in southern California. I. Results for the upper crust from $\mathrm{Pg}$ waves, Bull. Seism. Soc. Am. 76, 495-509.

Humphreys, E., R. W. Clayton, and B. H. Hager (1984). A tomographic image of mantle structure beneath Southern California, Geophys. Res. Letters 11, 625-627.

Lamanuzzi, V. (1981). Relative $P n$ travel time residuals for stations in Southern California, Masters Thesis, University of Southern California, Los Angeles, California.

Oliver, H. W. (1982) (Editor). Interpretation of the gravity map of California and its continental margin, Calif. Div. Mines Geol. Bull. 205.

Priestley, K. F., A. S. Ryall, and G. S. Fenzie (1982). Crust and mantle structure in the northwest Basin and Range province, Bull. Seism. Soc. Am. 72, 911-923.

Raikes, S. A. and D. Hadley (1979). The azimuthal variation of teleseismic $P$-residuals in Southern California: implications for upper-mantle structure, Tectonophysics 56, 89-96.

Vetter, U. and J. B. Minster (1981). Pn velocity anisotropy in Southern California, Bull. Seism. Soc. Am. 71, 1511-1530.

Walck, M. C. and J. B. Minster (1982). Relative array analysis of upper mantle velocity variations in Southern California, J. Geophys. Res. 87, 1757-1772.

Zoback, M. L., R. E. Anderson, and G. A. Thompson (1981). Cainozoic evolution of the state of stress and style of tectonism of the Basin and Range province of the western United States, Phil. Trans. R. Soc. Lond. $\mathbf{3 0 0}, 407-434$.

SEISMOLOGICAL LABORATORY

CALIFORNia INSTITUTE OF TECHNOLOGY

Pasadena, California 91125

Contribution No. 4196 